\title{
Editorial
}

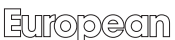

\section{Addiction Research and Socialpsychiatry Between Machiavelli and Modern Art}

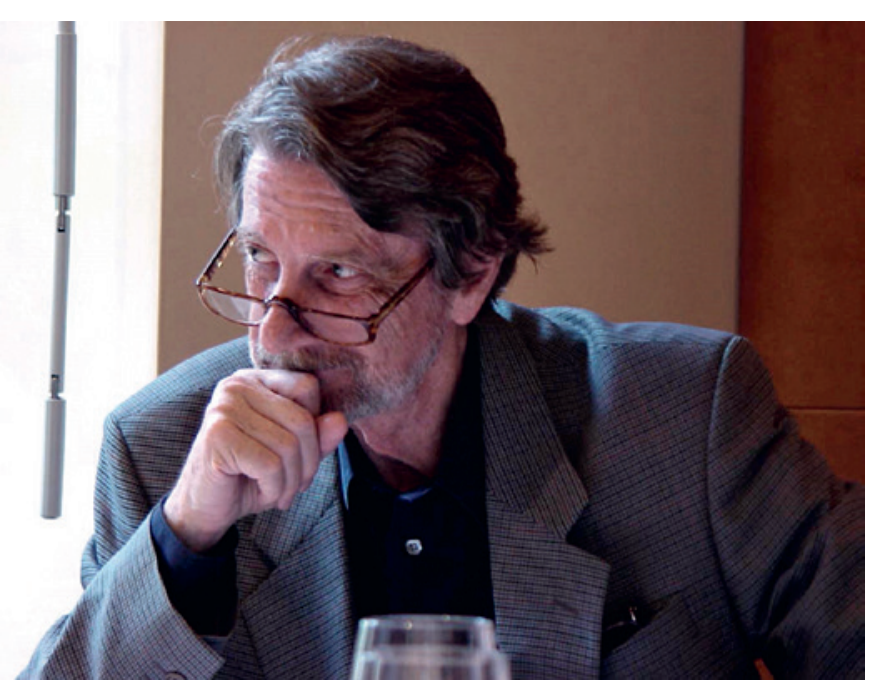

Ambros Uchtenhagen

Birthdays are for oneself, for one's companions and friends, and are often a reason for remembering the good old times, the wins and losses and memorable moments from different perspectives. From a less personal perspective, the career of an aspiring academician reflects the history of our discipline and the challenges driving it. Ambros Uchtenhagen's birthday was most likely a very spe- cial one, given the celebration in Zurich with guests and congratulations from the likes of Norman Sartorius, Jules Angst, Thomas Zeltner and Ruth Dreifuss honoring him on his 90th birthday in his hometown, the main stage for his Swiss and international role.

In the early nineties, Zurich was at the centre of public health crisis, as symbolized by the open drug scene in the beautiful Swiss town of "Platz Spitz". This sent a clear message that the drug policy needed a disruptive change to address issues such as rampant overdose and HIV crisis among drug users, and a new approach to the system of care. Ambros was the Chair for Socialpsychiatry at the University of Zurich then; he addressed the situation as a national urgency.

In today's North American overdose crisis, Psychiatry is not necessarily an active player in problem solving - but it became one in Zurich. Partnering with the community, political decision makers, enforcement, and citizens, a new model of collaboration emerged: the " 4 pillar approach". This bold endeavor broadened the range of treatment options and their accessibility.

Under his leadership, the Swiss Heroin Trial opened the road to regulation of heroin-assisted treatment in the early nineties, and he was instrumental in bringing more people into the treatment program using the academic and clinical tool kit. This was considered a highly contro- 
versial strategy then, when even methadone was seen as a threat in large parts of the world, including among some German and Swiss Psychiatrists.

A unique process started in Europe when Dutch, British, German and other psychiatrists joined and broadened the effort of establishing heroin-assisted treatment through clinical trials and political change to legal regulation. This was a major step towards ending the crisis and resulted in Switzerland having the lowest number of opioid overdose fatalities globally. It also contributed to the further acceptance and implementation of quality treatments in substance use in Europe, including heroin-assisted treatment being accepted and equipped with the strongest scientific evidence of all interventions in this field. In relation to the HIV epidemic, substitution was the single most successful measure to lower HIV incidence among intravenous drug users.

This changed the way the Europeans thought beyond prohibition, and was a starting point for a new way of networking, collaboration and science, which was reflected in a new journal "European Addiction Research". It underlined that European ideas and clinical concepts are essential for the future of this field globally. Key initiatives evolved from the old continent and inspired international colleagues from Portugal's drug policy to Dutch coffee shops, from safe injection sites to heroin-assisted treatment.

This was not the first paradigm shift Ambros was involved in. During his residency in the Burghoelzli and after promotion to "Oberarzt" under the then-head Manfred Bleuler, together with J. Angst and C. Ernst, he spearheaded Socialpsychiatry, shifting from big hospital asylums to community-based care. He initiated and imple- mented outpatient services, day clinics, and group homes for special clients creating an alternative system of care. After being a fertile ground for research and development for psychotherapy, Switzerland became a model for community mental health, especially for the most vulnerable in society. Switzerland, the small country in the middle of Europe, really became worth a journey beyond skiing or hiking. In the nineties it was especially inspirational for "change agents" in Psychiatry, particularly in Community Psychiatry and addiction treatment. Several initiatives inspired the necessary reform of services proving it could be done differently.

The fact that Ambros also studied Philosophy and wrote his $\mathrm{PhD}$ on Machiavelli might explain some of his achievements and success. Especially in Medicine, change is never only about good ideas. His compass and indicator for the quality of a society was always the wellbeing of the most vulnerable. A serious physician also needs to be an advocate, given how social determinants and stigma impact the effectiveness of health care and - in the end - the survival of our clients. This may sound a little dramatic, but today the number of overdose fatalities in the US and Canada are so high that it affects the life expectancy of a generation.

Being multi-talented may be the secret to such a career, in addition to the passion behind the talent. In recent years, Ambros turned towards painting again, an activity and passion which provides much quicker results than science or politics. And you can also let it flow, presenting your messages for everybody to see, which scientific journals do not always appreciate.

M. Krausz, Vancouver 